\title{
INFLUENCE OF MIXER TYPE AND TREATMENT TIME ON STRENGTH PROPERTIES OF FURAN COMPOUNDS
}

\author{
Martina HRUBOVČÁKOVÁ, Marianna BARTOŠOVÁ, Iveta VASKOVÁ, Martina DŽUPKOVÁ, \\ Branislav BUL'KO, Peter DEMETER, Dana BARICOVÁ
}

FMMR - Technical University of Košice, Košice, Slovak Republic, EU, martina.hrubovcakova@tuke.sk.

https://doi.org/10.37904/metal.2019.805

\begin{abstract}
History of foundry, as metal casting process, has a significant meaning regarding the overall history. With the gradual development of foundry processes, as well as improvement of technology and mechanical procedures, led to the creation of several technological epochs. Products of foundry are a part of our lives. The quality of mold has a significant impact on surface quality of the final casting. It is important to choose the most advantageous form of casting and type of mold, such as permanent, semi-permanent or single use, according to its size, shape and weight. In the process of production, uses second generation mold compounds, therefore consisting of molding sand and binder, which consists of furan resin and hardener. The ratio of these two components has a significant impact on treatment time and thus on overall producibility. Objective of mentioned experiments were to determine the ideal binder component ratio, and the ratio influence on treatment time, thus optimizing achieved results of treatment times and final strengths of molding mixtures.
\end{abstract}

Keywords: Foundry, moulding mixture, casting defect, furan

\section{INTRODUCTION}

Casting quality is an important aspect regarding technology and appearance. It's important to choose the most ideal means of manufacturing, from the start of the production process to achieve the desired casting quality, thus choosing the appropriate type of mold. In the process of mold making, we use three types of molds permanent, semi-permanent or single use. Foundry production gives the requirement of exploring the issues of single-use molds, where the main components regarding quality assessment are binder ratios - furan resin and hardener. The goal was to determine the ideal conditions of molding process to achieve stable hardness of molds. Usage of furan molding mixtures is not particularly widespread in Slovak Republic because of the initial cost, and complex technology in comparison with bentonite molding mixtures. The main advantage of second generation molding mixtures is its excellent renewability and longevity of molds and cores. By regular monitoring of workplace properties and treatment time of individual types of molding mixtures, we can achieve stable strength results and thus increase the production effectiveness [1].

\section{THEORETICAL PART}

Furan-based binders belong to second generation [2] of molding mixtures. As foundry binders, three types of furan resins are used: furan-amino-aldehyde - contains urea, it's used for molds and cores produced for grey iron castings, furan-ketone-aldehyde - consists of furfural, acetone and formaldehyde. It's considerably more expensive binder made for production of molds and cores for steel casting, furfural - used for production of cheap molding and core mixtures [3,4]. Furan is a heterocyclic organic compound with one oxygen atom in a five segment cycle. In ideal conditions it's very volatile and flammable, while the boiling temperature is $31.4^{\circ} \mathrm{C}$. It is slightly soluble in water, it's present in tar from spruce wood. [5,6,7]. Furan is toxic and carcinogenic its chemical formula is $\mathrm{C}_{4} \mathrm{H}_{4} \mathrm{O}$. Since furan is very aromatic, it reacts differently than other heterocyclic ethers. It's significantly more reactive than benzene. From all of furan derivatives, the most available is furoic acid aldehyde - furfural, from which by hydrogenation is acquired furfuryl alcohol $\mathrm{C}_{5} \mathrm{H}_{6} \mathrm{O}_{2}$ [8]. 


\subsection{Hardening process time periods of furan molding mixtures}

Individual sections of hardening process for self-curing mixures: Mixing period - it's the total mixing time, during which the resin and hardener in the molding mixture are homogeneously mixed, in the continuous mixer. At the beginning of the process catalyst and furan resin are added during continuous mixing (in the whirling mixer) and the reaction starts. Processing period - it begins with the start of the resin polymerization, and ends with compacting the mixture on the pattern. Every alteration of the state of compaction, even just a small shift of the compact layers, extends the processing period. Longevity - it's independent of the processing period and it's determined by the binder system reaction speed under given conditions of mold production. Longevity should always be longer than processing period. Disassembly period - it's finished at the moment, when the part of the mold is separated from the pattern and it's exposed to air. In that moment, the polymerization must be in an advanced state, in which the mold cannot be deformed anymore. Hardening period - is a period of time, when mold strength increases as a consequence of ongoing hardening reaction. It ends at the moment, when strength ceases to increase and the final strength is achieved (after 24 hours) [9],[10,11].

\subsection{Influence of mixer type and treatment time on strength properties of furan compounds figures, equations, tables}

Mixing of cold-hardened molding mixtures by resins in the continuous process has a rich history in foundry industry. In order to achieve high spatial strength stability with low binder consumption, high quality mixing machines are used.

\subsubsection{Spartan Omega}

Continuous mixer Spartan Omega III has crescent shaped jaws and door leading to mixing shaft are opening sideways which allows simpler cleaning and maintenance. Omega company distributes it in key, joint or mobile version, with starting capacity production from 1 to 100 tons of molding mixture per hour. Advantages of this mixer are: simple access to mixing shaft, higher mixer capacity, robust design, capacity 3 - 100 tones per hour [12]. Input of molding sand into the mixing shaft is provided by pneumatic cylinders, which insure typical fourway input: single sand : sand $1=100 \%$, usually new sand, single sand : sand $2=100 \%$, usually regenerated sand, sand mixture: sand $1=10 \%$, usually new sand, sand $2=90 \%$, usually regenerated sand [12]. Furan resin and hardener are added simultaneously to single mixing shaft. At request for mixture, joystick is pressed, main shaft motor turns on, blades start to spin. Pneumatic sand seal then opens and allows the dry sand to enter into the mixing canal. After this procedure resin and hardener pumps start. Catalyst is the first component that comes into contact with sand and its sprayed up the resin stream to mix with the first incoming sand. After that, as the sand is mixed with catalyst, resin is added into the mixture and mixed with the sand/catalyst mixture. The resulting mixture consisting of catalyst and resin is gradually by the blade rotation moved through the canal and at the end is put into the mold. When the desired amount of sand is added, joystick returns back to its original position and thus closing the sand pneumatic seal, stopping the resin pump as well as catalyst pump. Mixer shaft continues to rotate for the designated time period, thus evacuating the sand from the canal before it stops.

\subsubsection{AAGM wohr}

AAGM company is present on the market for more than 40 years and during this time, they adapted their continuous mixers to the most advanced foundry technologies. Continuous mixers are defined by their robust construction, simple operation, performance, longevity, efficiency and technical maturity. These features are reflected mainly on the molding mixture quality, minimal binder and catalyst usage, short course and mixing times and simple operation. AAGM company mixer has production capacity adjustable to 40 tons per hour maximum. On the other hand, Spartan Omega has more robust construction. Catalyst inlet is located in the upper mixing screw, thus the catalyst has more time to adsorb into the sand than in Omega, resin addition is done in the lower screw [13]. The next significant difference is the shape of the mixing shaft and screw, whose shape and arrangement of the blades plays a substantial role in mold mixture mixing process. 


\subsection{Sample measurement}

For acquiring molding mixture strength data, it was necessary to create samples which were subsequently examined in laboratory. These samples are made in wooden core. Core is placed under the mixer, mixture is compacted by its own weight, excess mixture is swept down and its left to harden on the core until desired shakeout strength is achieved. [12] After shaking out the samples (prisms), they are tied up with duct tape and labeled with data: furan resin concentration, PTS acid concentration, pouring time. Samples made in that manner are transported into the laboratory to undergo a flexural strength trials. These are carried out by personnel in two periods, after fourth hour and after 24th hour [12].

Strength detection test by testing pressure strength is most common industrial test. The method is that pressure is generated on the normalized prism of known chemical composition until the mentioned sample is broken. Set measurement times must be abided as accurately as possible. For optimal results 4 and 24 hour intervals are used, while 24 hour interval is called final strength. That means that molding mixture achieved its maximum strength after 24 hours. [14] Samples prepared in this manner are moved to laboratory for flexural strength testing. This test is carried out by a worker in two intervals, after 4th and 24th hour.

\section{COMPARISON OF ACHIEVED RESULTS}

Molding mixtures measurement results were categorized into two groups, by treatment time and by strength. Subsequently they were divided by given of used binder and mixer on which the mixture was mixed. To increase the effectiveness of the production process, dosage values of the binder and hardener are pre-set into predetermined programs. Every single casting has separately determined values by which these components are dosed, dosage program is picked based on: casting size, mold size, customers request.

The sand is at the beginning of the working hours cold, especially during winter months, when its only $6{ }^{\circ} \mathrm{C}$. That's why first molds are those with larger measurements, where treatment time does not influence the effectiveness of the work. Measurements were divided into several groups and subgroups. First measurement group is focused at Spartan OMEGA mixer, at its treatment times and strength measured from several different samples. Second group is focused at AAGM WOHR40 mixer where treatment time and strength measurement results are depicted. In third group, comparison between workability and strength with the same component dosage is shown.

\subsection{Comparison of treatment time and strength using the same dosage.}

Furan resin with use of furan U204 and hardener 3423, 100T3 was chosen for comparison of the achieved results, Figures 1 - 4.

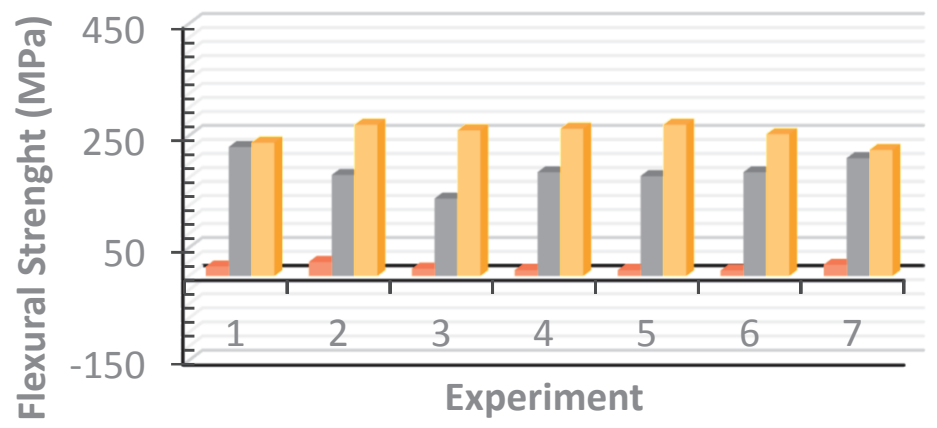

Figure 1 Furan type U204, acid type 3423, Spartan OMEGA III 


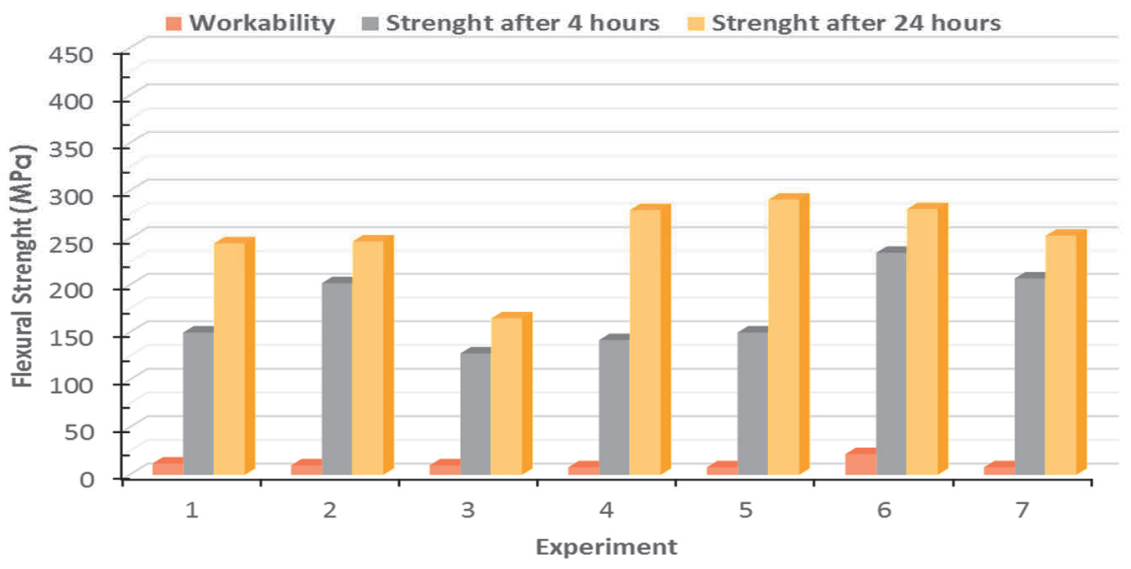

Figure 2 Furan type U204, acid type 3423, WOHR 40

Values of strength after 4 hours are lower, because hardening reaction was not able to harden all of the components of the molding mixture in such a short time. The final strength meets values, which are expected from given component dosage.

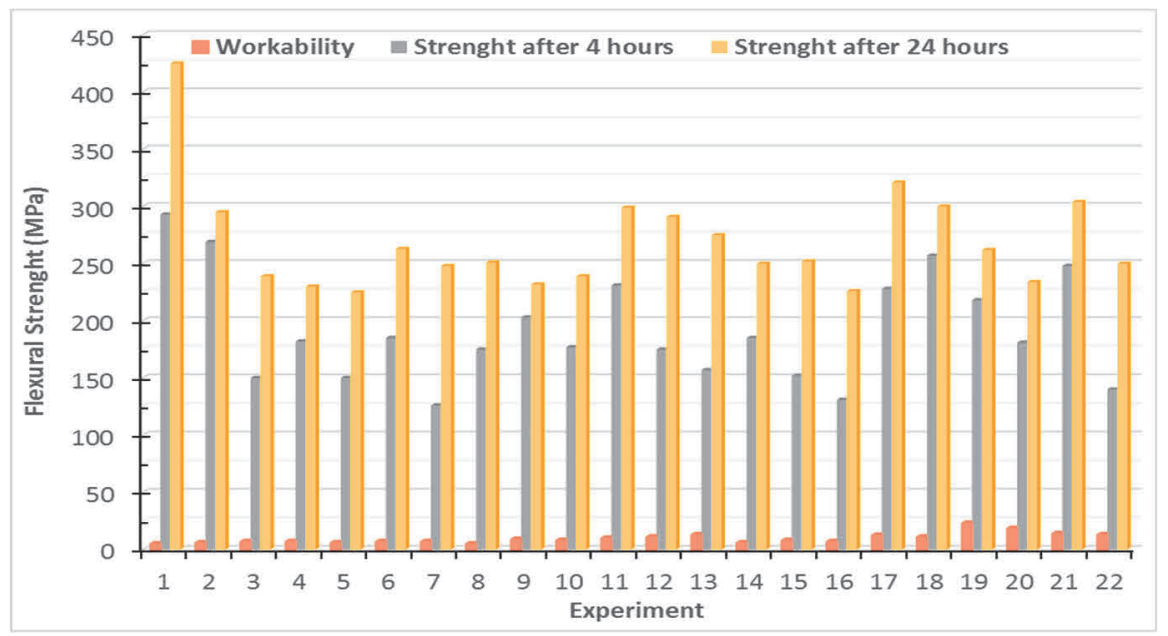

Figure 3 Furan type U204, acid type 100T3, Spartan OMEGA III

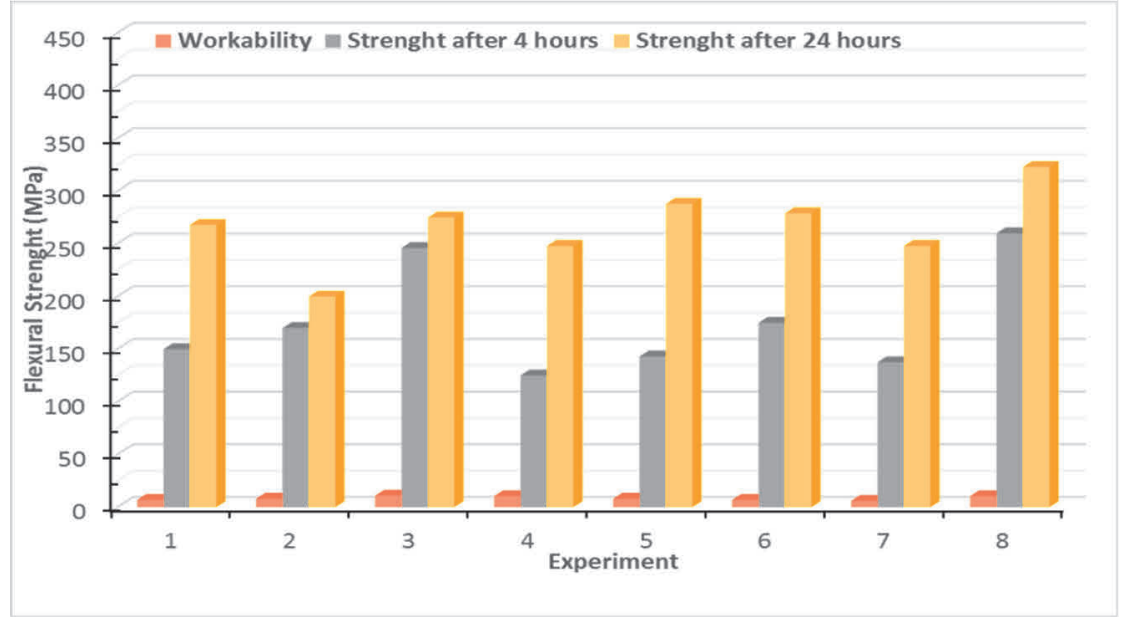

Figure 4 Furan type U204, acid type 100T3, WOHR 40. 


\section{CONCLUSIONS}

The goal was to determine the influence of mixing machine and other factors on treatment time and thus on final strength properties of molding mixture. Mixer Spartan Omega III is more recent, technologically advanced and is able to dose hardener in proportion to furan resin according to the sand temperature. By using warm sand, problems with low treatment time or vice versa with long treatment time are a non-issue. Measured data show, that the biggest influence on workability of the molding mixture has the temperature. This is a temperature of the environment, new sand, regenerated sand but mainly casting flasks. The issue of casting flasks rests on the fact, that during winter months they have low temperatures, which slows down the hardening reaction or stops it entirely. There are cases when the molding mixture at the center of the mold is allready hardened, but not on the sides. This stretches the treatment time and delays the dissasembly time of the mold.

During summer there is an opposite case, when warm casting flasks accelerate the treatment time, which increases the risk of breaking the primary strength bonds during molding. To achieve stable treatment times, it is necessary to choose ideal combinations of furan resins and hardeners based on their reactivity.

During winter months must be used more reactive types, for example with simultaneously used resin Kaltharz XA20 and hardener 100T3, at very low temperatures hardener 500T1 (highly reactive) and during summer months Kaltharz U204 or Askuran in combination with less reactive acids such as 3423 . By regular measurement of treatment time and strength values, and choosing the correct default programmes, it is possible to achieve stable results of strength properties of molds.

\section{ACKNOWLEDGEMENTS}

This paper was prepared under grant project No.1/0868/17 with financial support of VEGA MŠ SR and SAV.

\section{REFERENCES}

[1] CAREY, P., LOTT, M. Foundry Management \& Technology, 26, 1995.

[2] Mancuso Chemicals: Foundry products - Technical data sheet, 2005, Canada.

[3] VASKOVÁ, I., HRUBOVČÁKOVÁ, M., MALIK, J., EPERJEŠI, S. Influence of technological parameters of furane mixtures on shrinkage creation in ductile cast iron castings. Archives of metallurgy and materials. 2014. vol.59, issue 3, pp. 1037-1040.

[4] KUBECKI, M., HOLTZER, M., ŹYMANKOWSKA-KUMON, S. Investigations of the temperature influence on formation of compounds from the BTEX Group During the thermal decomposition of furan resin. Archives of Foundry engineering. 2013.vol. 13, issue 2, pp.85-90.

[5] DZIAKOVÁ, M., VASKOVÁ, I., FECKO, D. Influence of Operating Factors on Properties of Furan Mixtures. Acta Metallurgica Slovaca. 2010. Košice, vol. 16, No. 1, pp. 58-63.

[6] SOCHA L., VODÁREK V., MICHALEK K., FRANCOVÁ H., GRYC K., TKADLEČKOVÁ M., VÁLEK L.. Study of Macro-Segregations in a Continuously Cast Billet. Materiali in Tehnologije. 2017. vol. 51, issue 2, pp. $237-241$.

[7] GHOSH, D. Modern Furan for Modern Castings. In TRANSACTIONS OF $61^{\text {st }}$ INDIAN FOUNDRY CONGRESS. Haridwar, India, 2013, pp. 1-4

[8] ODEHNAL, J., SOCHA, L., GRYC, K., ŠURAL, R., BULÍN J., STRAKA, J. Influence of Refining on Achieving Low Oxygen Contents at Production of Special Steels for Energetic Industry. In METAL 2018: 27th International Conference on Metallurgy and Materials. Ostrava: TANGER, 2018, pp. 93-101.

[9] GRYC, K., STROUHALOVÁ, M., SMETANA, B., SOCHA, L., MICHALEK, K. Influence of Direct Thermal Analysis Experimental Conditions on Determination of the High Temperature Phase Transformation Temperatures. Archives of Metallurgy and Materials. 2015. vol. 60, issue 4, pp. 2867-2871.

[10] CHANDA, M., DINESH S. R. Monitoring he curing of furan resins through the exothermic heat of reaction. Macromolecular Materials and Engineering. 1978. Vol. 69., Issue 1., pp. 85-98. 
[11] DUNLOP, A.P., PETERS, F.N. The Furans.American Chemical Society Monograph Series. $1^{\text {st }} . e d$. New York. Reinhold Publishing Corporation, 1953. p. 867

[12] Verlag Stahleisen GmbH, Giesserei-rfahrungsaustausch, 2006, Düsseldorf, pp. 12-17.

[13] DZARMAGOWSKI, M., ZAWADA, B. Possibilities for the utilisation of steelmaking slags for the production of slagforming materials. Archives of Metallurgy and Materials, 2009, Vol. 54, No.3, pp. 829-836.

[14] NYKIEL, A.S, NYKIEL, M. Study of hydroxyapatite behaviour during sintering of 316L steel. Archives of Foundry Engineering, 2010, vol.10, Special Issue 3, pp. 235 - 240. 